\title{
Entamoeba histolytica liver abscess
}

\section{Dianne Fang HBSc, David Shu MD}

Previously published at www.cmaj.ca

See also practice article by Broz and colleagues

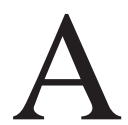

39-year-old woman presented to the emergency department with a five-day history of fever, chills, diarrhea, and pain in the right shoulder and right upper quadrant of her abdomen. Four months earlier, she had returned from Puebla, Mexico, where she had been studying for five months. She had had abdominal pain and diarrhea in Mexico, and infection with an intestinal parasite had been diagnosed clinically. She had been given probiotics, an antidiarrheal agent and a seven-day course of nitazoxanide. After returning to Canada, she continued to have abdominal discomfort and loose stools. Entamoeba histolytica IgG was found on serologic testing, and computed tomography (CT) showed no signs of a liver abscess. She was given metronidazole and iodoquinol, but she stopped treatment after three days because of adverse effects from the medication. Two months later, she presented to the emergency department as described above.

On physical examination, the patient had generalized abdominal tenderness and dry mucous membranes, and her temperature was $39.5^{\circ} \mathrm{C}$. Laboratory examination showed a leukocyte count of 17.1 (normal 4.5-11.0) $\times 10^{\circ} / \mathrm{L}$ and liver enzyme levels at 1.5 times normal. A CT scan showed a multi-septated abscess in the liver (Figure 1); the abscess was drained percutaneously, and $140 \mathrm{~mL}$ of watery-brown fluid was aspirated. The fluid was reactive to E. histolytica $\mathrm{IgG}$, but the results of smear and culture tests were negative for parasites, bacteria and fungi. The results of blood cultures and stool microscopy for intestinal parasites were also negative. The patient was prescribed oral treatment with metronidazole, a tissue amebicide, for 10 days. This was followed by 21 days of oral treatment with iodoquinol, which eradicates any surviving luminal cysts. Within one week, her symptoms improved. A CT scan taken 16 days later showed that the abscess had decreased in size.

The possibility of amebic liver abscesses should be considered if a patient returns from the tropics with a fever. ${ }^{1}$ E. histolytica usually colonizes the gastrointestinal tract without producing symptoms. However, up to 1 in 10 patients with an untreated, asymptomatic infection will have invasive disease, usually liver abscesses, within one year. ${ }^{2,3}$

From the Department of Medicine, University of British Columbia, New Westminster, BC

CMAJ 2010. DOI:10.1503/cmaj.091926

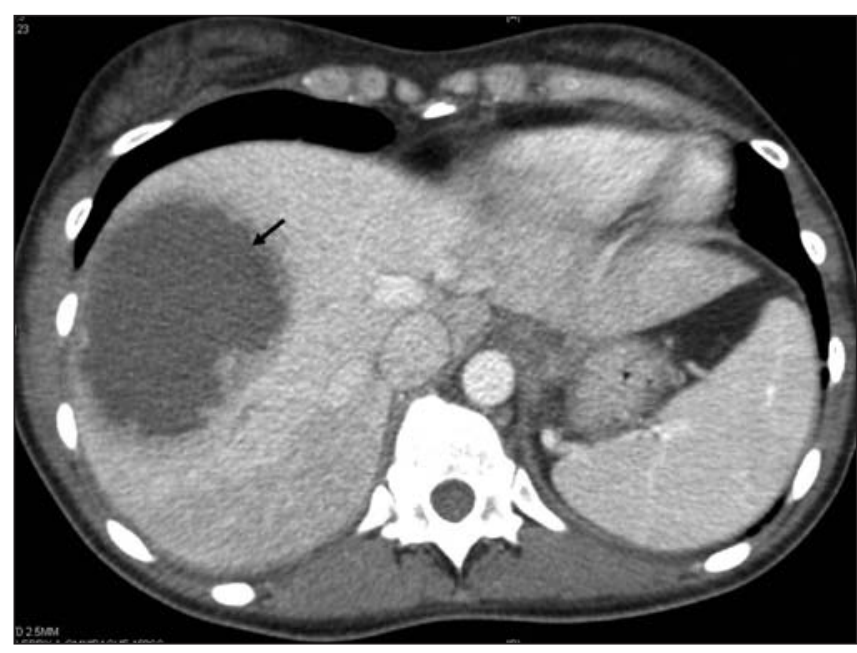

Figure 1: A computed tomography scan showing a multiseptated abscess (arrow) in the liver of a 39-year-old woman with Entamoeba histolytica infection.

Ultrasonography and CT scanning are equally sensitive at detecting liver abscesses, but confirmation of amebic infection with serum antibody detection is recommended. ${ }^{2}$ Many amebic infections thought to be E. histolytica can be attributed to morphologically similar, nonpathogenic species. ${ }^{3}$ A specific and sensitive test, such as polymerase chain reaction, is required to accurately detect pathogenic E. histolytica. ${ }^{3}$

Treatment guidelines for amebic liver abscesses recommend treating suspected cases empirically, based on history, epidemiology and imaging of an abscess, with a nitroimidazole followed by a luminal amebicide.'

This article has been peer reviewed.

Competing interests: None declared.

\section{REFERENCES}

1. Johnston V, Stockley JM, Dockrell D, et al. Fever in returned travelers presenting in the United Kingdom: Recommendations for investigation and initial management. J Infect 2009;59:1-18.

2. Chavez-Tapia NC, Hernandez-Calleros J, Tellez-Avila FI, et al. Image-guided percutaneous procedure plus metronidazole versus metronidazole alone for uncomplicated amoebic liver abscess [review]. Cochrane Database Syst Rev 2009;(1):CD004886.

3. Gonzales MLM, Dans LF, Martinez EG. Antiamoebic drugs for treating amoebic colitis [review]. Cochrane Database Syst Rev 2009;(2):CD006085. 